\title{
Eski Uygurlarda Mani Yazısının Gelişimi
}

\author{
Betül ÖZBAY*
}

\section{$\ddot{O} \mathbf{z}$}

Manihaizm ve Manihaist metinler hem İran hem de Türk dilleri araştırmacıları için önemli bir çalışma sahasıdır. XX. yüzyılın ilk yarısında Çin'deki Uygur Özerk bölgesinin doğusunda bulunan Turfan Vadisi'nde özellikle Alman arkeoloji ekiplerince yapılan keşiflerde Eski Uygur Kağanlığı döneminden kalan son derece değerli, sayısız el yazması ve arkeolojik parça bulunmuştur. Bulunan bu eserlerin büyük bir bölümü Avrupa'daki müze ve araştırma merkezlerine getirilmiştir. Günümüzde, Manihaist metinlerin saklandığı en büyük arşivler Berlin Brandenburg Bilimler Akademisindeki Turfan Araştırmaları Merkezi ile Berlin Asya Sanatları Müzesinde yer almaktadır. Bu oldukça çeşitli eserlerin bulunduğu büyük arşivlerde Manihaist İran ve Türk külliyatına ait hem dinî hem de din dışı içerikli pek çok yazma eser mevcuttur. Makalemizde, Mani yazısının kökeni, Mani harfleri, sayılar ve diğer işaretlerin metinlerdeki görünümü genel olarak anlatılmıştır. Ayrıca, yazı geleneğinin nasıl geliştiği ve değiştiği hem İran hem de Uygur metinlerinden alınan örneklerle karşılaştırmalı olarak sunulmuştur. Makalede çalışılan eserler temel olarak Berlin Brandenburg Bilimler Akademisi, Turfan Araştırmaları Merkezinin koleksiyonundaki parçalardan oluşmaktadır. Bu ça1ışmada incelenmiş olan metinler şu şekildedir: M17, M172, M47, Şapuragan metni, M473, M475, M477, M482, M472, M470 (Orta Farsça); M5, M6, M47 (Partça); M178, M172 (Soğdca); U74, Huastuanift Londra ve Berlin fragmanları (Eski Uygurca).

Anahtar Kelimeler: Mani yazısı, Eski Uygurca, Orta İran Dilleri, Turfan Yazmaları, Paleografi

\footnotetext{
* Dr. Öğr. Üyesi, İstanbul Medeniyet Üniversitesi, Edebiyat Fakültesi, Türk Dili ve Edebiyatı Bölümü, Türkiye.
} Eposta: betul.ozbay@medeniyet.edu.tr. https://orcid.org/0000-0003-1513-0994 


\title{
The Development of Manichean Script in Old Uyghurs
}

\begin{abstract}
Manichaeism and Manichean texts are important fields of study for the researchers of both Ancient Iranian and Turkic languages. During the first half of the 20th century, numerous extremely valuable manuscripts and archaeological items from the Old Uyghur Kingdom period were found in the Turfan oasis located in east of Uyghur Autonomous Region in China especially in expeditions by German archaeological teams. Most of these works were brought to the museums and research centers in Europe. Today, the largest archives of Manichean texts are located in the Turfan Studies department of BerlinBrandenburg Academy of Sciences and Humanities and the Museum of Asian Art in Berlin. In these large archives of various works, there are many manuscripts containing both religious and non-religious texts belonging to the Manichean Iranian and Turkic corpus. In our article, the origin of Manichean script, the appearance of Manichean letters, numbers and the other signs in the texts are explained in general. Furthermore, how the tradition of writing had developed and changed was comparatively explained with examples taken from both Middle Iranian and Old Uyghur texts. The texts studied in this study are mainly from the collection of Turfan Studies department of Berlin-Brandenburg Academy of Sciences and Humanities. In this paper the following texts were analyzed: M17, M172, M47, Shapuragan text, M473, M475, M477, M482, M472, M470 (in Middle Persian); M5, M6, M47 (in Parthian); M178, M172 (in Sogdian); U74, London and Berlin fragments of Xwastwanift (in Old Uyghur).
\end{abstract}

Keywords: Manichean script, Old Uyghur language, Middle Iranian languages, Turfan Manuscripts, Paleography 


\section{Extended Summary}

Manichean texts were written in many different languages, but the most important religious texts were usually attested in Middle Iranian and Old Uyghur languages in Central Asia. After the conversion of famous Uyghur Kagan Bögü, a significant amount of Manichean texts were translated into Old Uyghur language from Middle Iranian languages, especially from Parthian, Middle Persian and Sogdian. Manichean texts were mainly attested in the Manichean script which shares the same origin with the other Semitic scripts. Like the other Semitic scripts, Manichean script is also a consonant based alphabet. The Iranian scribes made some changes on the original script according to Iranian languages. However, the script later was reorganized by Old Uyghur scribes for the Turkish language in the Turfan region. Therefore, it was used for the Middle Iranian and Old Uyghur languages with some differences; mostly the phonological structures of these languages caused these differences. A comparative paleographical analysis can show us what kinds of reasons cause these varieties, and how they reveal in the texts.

In this paper, the development of the paleographical and orthographical features of the Manichean script in Middle Iranian (Middle Persian, Parthian, Sogdian) and Old Uyghur texts were comparatively presented. The findings which were given here mainly based the doctoral thesis of "The Paleographical Analysis of the Manichean Script for Middle Iranian and Old Uyghur Texts" presented in Istanbul, Y1ldiz Technical University in 2016. Due to time limitations, only some important texts in both languages were analyzed. While we were choosing these texts, we essentially looked at the appearance and entirety of the texts in each language. In general, the writing styles and the functions of the letters of the script were analyzed. Our main corpus consists of the fragments from the collection in The Berlin-Brandenburg Academy of Sciences and Humanities, but we also scanned other Dunhuang manuscript collections from other places such as the British Library, as well. 
As we pointed out above, we mainly focused the writing styles and the functions of the letters for the analysis of the script. Therefore, we studied the following texts: Middle Persian: M 17, M 172, M47, Shabuhragan fragments M 473, M 475, M 477, M 482, M 472, M 470; Parthian: M 5, M 6, M 47; Sogdian: M 178, M 172; Old Uyghur: Xwastwanift London bookroll, Xwastwanift Berlin fragments U 8, U 9, U 10, U 7; Windgod U 74. Except M 47, all these texts were written in Manichean formal script. However, M 47 was written in cursive script and according to our findings, it is the closest text to the Manichean "late hand" script from that period.

Furthermore, the Uyghur scribes developed a very clear back and front vowel system from a consonant based script for Turkish. The Manichean script was adapted to Turkish by using different combinations of the letters, adding diachronic points and improving new functions of the letters. On the other hand, although not as detailed as the Manichean script, we can see some discrimination between back and front vowels also in Uyghur script in a couple of letters such as "k" (with front vowels) and "q" (with back vowels).

In this study, the basic results were presented rather than giving long analysis. According to our results, we can say that the latest orthographical features can be found in Old Uyghur texts for Manichean script. In these texts, it can be said that there is certain discrimination between the vowels and consonants which we cannot find in Iranian texts. Moreover, the Uyghur scribes developed a very clear back and front vowel discrimination system from a consonant based script. On the other hand, this vowel discrimination feature is specific to Old Uyghur language, it is not observed in Middle Iranian Turfan texts. 


\section{Giriş}

Orta Asya'nın güneydoğusunda yaşamış Eski Uygurlar IX.-XIII. yüzyı1lardan günümüze ulaşabilen son derece kıymetli eserler bırakmıştır. ${ }^{1}$ Turfan Vadisi adı verilen bölgede bulunmuş Türk kültür tarihi için paha biçilemez nitelikteki bu arkeolojik eserler bölgenin zengin kültürünün aynası niteliğindedir. Vadi’de bulunan Eski Uygur dilindeki eserler Uygur, Mani, Türk Runik, Çin, Brahmi, Süryani gibi oldukça çeşitli yazılarla yazılmıştır. Özellikle bu kadar farklı yazılarla üretilmiş metinler, bugün bile araştırmacıları en çok etkileyen unsurlardan biridir. Öte yandan, bölgenin bir diğer önemli özelliği olan inanç çeşitliliğinin fazlalığı da metinlerin yazıldı̆̆ı yazıların değişmesine neden olmuştur. Farklı dinlere inanan insanlar için inanç hem metinlerin içeriğini hem de yazı tipini belirleyen temel unsurdur. Örneğin, Manihaist Uygurlar metinlerini ağırlık olarak Mani yazısıyla yazmakla birlikte Türk Runik, Uygur, Soğd gibi diğer yazı türlerini de kullanırlarken Budist Uygurlar çoğunlukla Uygur yazısını tercih etmişlerdir. Eski Uygurlar döneminde en çok kullanılan yazı, Soğd yazısından geliştirilmiş olan Eski Uygur yazısıdır. Hem dinî hem de din dışı eserlerin yazımında çoğunlukla bu yazı tercih edilmiş olmasına rağmen çok geniş bir yazma eser koleksiyonu bırakan Manihaist Uygurların kullandıkları Mani yazısı da en az bu yazı kadar dikkate değerdir.

Manihaistler, hiçbir zaman Budistler kadar geniş kitlelere ulaşamamış olsa da Eski Uygurlar arasında ayrıcalıklı bir konuma sahip olmuşlardır. Turfan Vadisi'nde bulunan Manihaist içerikli metinler türlü dillerde yazılmış olmalarına rağmen özellikle Eski Uygurca ile Soğdca, Partça, Orta Farsça gibi çeşitli Orta İran dillerindeki eserler çoğunluktadır. Manihaizm, Eski Uygurlara altın çağını yaşatmış olan Bögü Kağan zamanında resmen devlet eliyle desteklenmiş ve dinin doğru öğrenilmesi için dinî eserlerin önemli bir kısmı Eski Uygurcaya tercüme edilmiştir. Bugün elimizde bulunan bazı metinlerde bu desteğin izlerini görebilmekteyiz. Örneğin, Berlin Bilimler Akademisinin (BBAW) koleksiyonunda bulunan U 72 arşiv numaralı yazmada yer alan aşağıdaki bölüme göre Bögü Kağan tebaasından Manihaizm'e iman etmesini açıkça istemektedir:

1 Bu makale öz olarak, 2010 yılında sunulan Maniheist Uygur Metinlerinin Envaterinin Hazırlanması ile 2016 yılında sunulan The Paleographical Analysis of the Manichean Script for Middle Iranian and Old Uyghur Texts adlı lisansüstü tezlerinde elde edilen bulguları içermektedir. 
[taqï] ymä m(ä)n k(ä)lt(i)m ornuma olordum [sizlärkä] y(a)rliqqayur m(ä)n dendarlar sizlärkä [nä] [sözlä]sär ymä üzüt asï̈̈̈na t(a)vratsar s[izlärkä den]qa t(a)vratsar ötläsär sizlär olar savïn-[ča] ötinčä yorïylar ymä amranmaq bili-

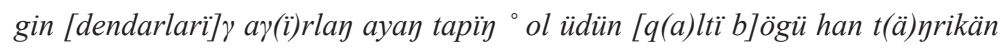
bo y(a)rl(i)y y(a)rlïqaduqta [ötrü ü]küš quvray q(a)ra bodun t(ä)yri eligkä yükünü [ötü]ndilär ymä ayqürdillar , ymä bizi' ’ä [dendarlar] qa yüküntilär s(ä)vinč ötüntilär (U 72/V/2-11)

“... 'Dahası ben geldim, tahtıma oturdum ve (şimdi) sizlere (şöylece) emrediyorum: rahipler sizlere ne söylerse ve ruh(un) yararı için ne tembihlerlerse, (nasil) tavsiye ederlerse onların sözleri ve ihtarları doğrultusunda davranın. Ayrica sevgi ve şefkatle (rahipler)e hizmet edin, saygı gösterin. 'O zaman Bögü Han bu emri verdiği için kalabalık topluluk ulu hükümdara hürmetle, (tazimle) eğilerek haykırdılar. Biz rahipleri saydılar, sevdiler." (Özbay, 2014: 33)

Bu alıntıda da gördüğümüz gibi Bögü Han Manihaist rahiplere saygı gösterme, onların tavsiyeleri doğrultusunda yaşama buyruğunu net bir biçimde dile getirmiştir. ${ }^{2}$ Fakat yine de bu resmî buyruğa rağmen Manihaizm Uygurlar arasında hiçbir zaman büyük inanır kitlelerine ulaşamamıştır. Çoğunlukla, zenginlerin desteğinde küçük bir kesime hitap edebilmiştir. Eski Uygur eşrafının verdiği maddi, manevi desteklerse bugün bile arkeoloji, sanat tarihi, tarih, dil, edebiyat, teoloji gibi çok çeşitli sahalardan araştırmacıların üzerine çalışmaya devam ettikleri muazzam eserler üretmelerini sağlamıştır.

\section{Mani yazısının kökeni}

Eski Uygurlar tıpkı Uygur ve Soğd yazıları gibi Sami kökenli olan Mani yazısını da yine Soğdlardan öğrenmişlerdir. Fakat Mani yazısının İran dilleri için kullanılan hâli olduğu gibi kopyalanmamış, Türkçeye daha uygun olacak şekilde geliştirilmiştir. Eski Uygur Mani yazısında İran metinlerinde görmediğimiz farklılıklar bulunur. Özellikle, Türkçede ziyadesiyle önemli ve belirleyici fonetik unsur olan art ve ön sıradan ünlülerin ayrımı Mani yazısında geliştirilen birtakım yeni yazı karakterleriyle oldukça açık bir şekilde yapılır. Ancak ne yazık ki yine bu yazıda da Türkçe metinlerin yazıldığı diğer pek çok yazı gibi geniş ve dar yuvarlak ünlülerin gösterimi için özel bir işaret yoktur. 1904 yılında Turfan'da bulunan Manihaist metinleri ilk kez tanıtan F. W. K. Müller Mani yazısının Estran- 
gelo yazısının bir versiyonu olduğunu makalesine verdiği şu başlıkla ifade eder (Müller, 1904: 1):

Handschriften-Reste in Estrangelo-Schrift aus Turfan, Chinesisch-Turkestan

“Çin-Türkistanı Turfan'dan Estrangelo yazısıyla yazılmış el yazması kalintıları"

Ancak sonraki araştırmalarda bu yazının Suriye bölgesinde gelişmiş ve kullanılmış olan Palmira yazısının yumuşak yüzeye uygun bir biçimi olduğu fark edilmiştir (krş, Durkin-Meisterernst, 2000: 161-178 ve 2014: 29-40). Aşağıdaki resimlerde Palmira, Estrangelo ve Mani yazılı metin örnekleri gösterilmektedir:

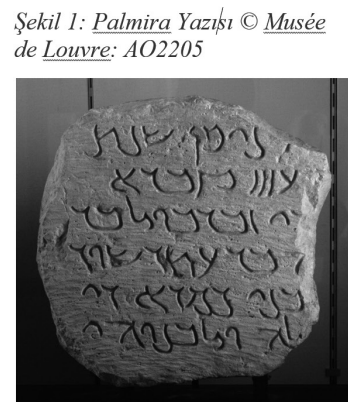

Şekil 2: Estrangelo yazısı (CLibrary of Congress, Washington, D.C., Encyclopoedia Britannica

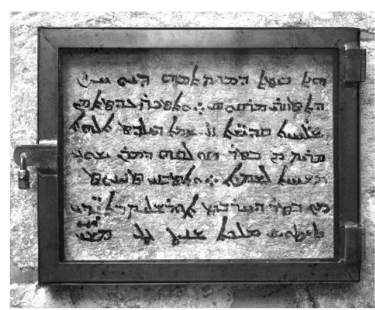

Şekil 3: Mani Yazısı $@$ C BBAW

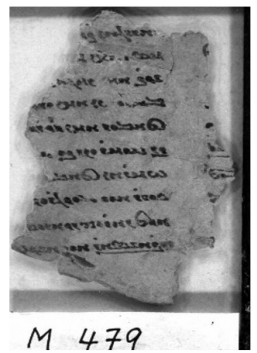

\section{Mani yazısında harfler}

Mani yazısı genel olarak Manihaizm dinine inananların kullandığı bir yazı olmuştur. Turfan'da Orta Farsça, Soğdca, Partça, Baktriyaca, Yeni Farsça ve Eski Uygurca gibi türlü dillerde Mani yazısıyla yazılmış çok sayıda metin bulunur. Bunun dışında, yazı Mezopotamya'da ve Mısır'da bulunan Mani yazılı şifa çanakları ile yine bu bölgede Süryani dilinde yazılmış bazı yazmalarda da kullanılmıştır. Her ne kadar dillere göre harflerin sayısı farklılaşabilse de aşağıda Orta İran dillerinde kullanılan Mani yazısında bulunan 23 temel işaret yer almaktadır: ${ }^{3}$ 
Şekil 4: Mani harfleri (săgdan sola doğru sirastyla): $a, b, g, d, \underline{h} w, z, j, h, t, y, k, l, m, n, s, \underline{a v n}, p, c ̧, q, r, s, t$

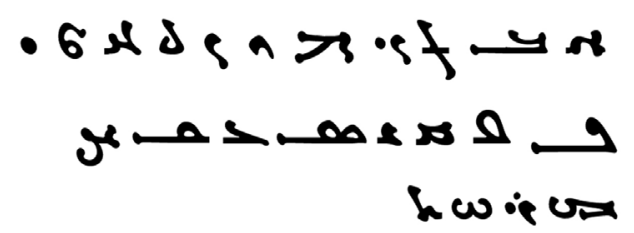

Bu harflerin dışında, Turfan'daki Mani yazılı Eski Uygurca metinlerde aşağıdaki ilave işaretler de bulunur:

Şekil 5: Ilave harfler (sağdan sola sirastyla): $\beta, \gamma, h, \delta, \delta \underline{\delta}, \tilde{k}, \ddot{q}$

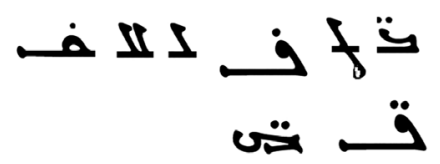


İlave edilen bu işaretlerle birlikte Eski Uygurların kullandıkları Mani yazısının temel karakterleri aşağıdaki gibi olmuştur (Özbay, 2019: 55-56):Tablo

\begin{tabular}{|c|c|c|c|}
\hline Yazı cevirisi karşlukları & Basta & Ortada & Sonda \\
\hline $\mathrm{a}$ (elif) & se, sent & " & " \\
\hline$\ddot{a}$ (clif) & * & " & " \\
\hline b & $=$ & $=$ & 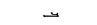 \\
\hline $\mathrm{f}(\mathrm{c})$ & $v, u$ & $v, v$ & ex, $x$ \\
\hline $\mathrm{d}(\mathrm{\delta})$ & II & II & ה \\
\hline $\mathrm{d}$ (dal/dalet) & • & • & ?, \\
\hline $\mathrm{f}$ & $\rightarrow$ & ف ف ف & $\rightarrow$ \\
\hline $\mathrm{g}$ & 1 & $t$ & $t$ \\
\hline $\mathrm{g}(\gamma)$ & $d$ & $\frac{1}{2}$ & t \\
\hline $\mathrm{b}$ & * & * & $*$ \\
\hline $\mathrm{h}(\mathrm{b}, \mathrm{x})$ & 3 & $\rightarrow$ & $\rightarrow$ \\
\hline b & . & . & $x$ \\
\hline $1, \mathrm{i}, \mathrm{e}$ & $\Delta$, & $\bullet, \cdot$ & - \\
\hline $\mathrm{j}(\mathrm{z})$ & $\Delta, \bar{s}$ & $d, \bar{s}$ & $\Delta, \ddot{z}$ \\
\hline $\mathrm{k}(\mathrm{q}, \mathrm{k})$ & $\rightarrow$ & 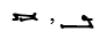 & $\longrightarrow$ \\
\hline $\mathrm{k}(\ddot{\mathrm{q}}, \overline{\mathrm{k}})$ & ت & ت & تـ, ت \\
\hline 1 & $\Omega$ & $\Omega$ & $\Omega$ \\
\hline $\mathrm{m}$ & $\triangle$ & $\triangle$ & us \\
\hline $\mathrm{n}$ & . & * & ' \\
\hline $\mathrm{o}, \mathrm{u}$ & are & . & . \\
\hline $\bar{o}$, ü & 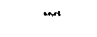 & on, a & . \\
\hline $\mathrm{p}$ & $\rightarrow$ & ص & $\rightarrow$ \\
\hline $\mathrm{r}$ & + & + & $\dot{i}, \dot{*}$ \\
\hline$s$ & $\infty$ & $\infty$ & $\rightarrow$ \\
\hline$s(s)$ & s & $\omega$ & $\omega$ \\
\hline $\mathrm{t}$ & h & h & b \\
\hline$\underline{t}$ & $b, 6$ & $b, b$ & b, $, 2,2$ \\
\hline $\mathrm{v}(\beta)$ & $y$ & $\bar{y}$ & تשت \\
\hline w & . & . & r \\
\hline y & • & •, , & - \\
\hline $\mathrm{z}$ & s & ' & , \\
\hline ' (ayn) & $=$ & & \\
\hline
\end{tabular}

1: Eski Uygurlarda Mani Yazısı 
Yukarıda görüldüğü gibi alfabetik bir yazı olan Mani yazısı da tipik bir ünsüz temelli Sami yazısıdır ve dokuz vokalli bir dil için yeterli ünlü işareti yoktur. $\mathrm{Bu}$ nedenle Manihaist Uygurlar özellikle ünlü ayrımlarını daha iyi yapabilmek için birtakım ilave işaretler ve bazı harfler için geliştirilen yeni işlevlerle yazıy1 Türkçeye daha uygun hâle getirmişlerdir. Örneğin, Şekil 4 ve 5 'te yer alan $q$ ve $k$ ünsüz çiftlerinin noktasız biçimleri düzenli olarak ön sıradan ünlülerle kullanılırken aynı işaretlerin noktalı biçimleri (“"̈" ve "“̈”) art sıradan ünlülerle kullanılır ve bu kullanım Türkçe metinlere özgüdür. Yine İran metinlerinde tıpkı Arap harflerindeki waw 9 işareti gibi hem çift dudak $w$ 'si hem de $o, u$ gibi yuvarlak ünlüler için kullanılan "w" harfi, Uygur metinlerinde, sözcük eğer alıntı bir dinî terim değilse, yalnızca yuvarlak ünlüleri gösterir. Uygurlar diş dudak v'si için Soğdların kullandığı “ $\beta$ ” işaretini kullanılmıştır, örneğin:

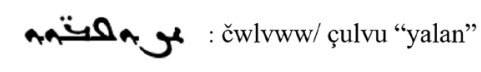

Sağdan sola yatay olarak yazılan bir alfabe olan Mani yazısındaki harflerin paleografik özellikleri çeşitlenebilmesine rağmen temelde standart (formal) ve italik (el yazısı, eğik, kursiv) olmak üzere iki ana yazı tarzı vardır. Özellikle mektuplarda karşılaştığımız belli bir açıda eğik olarak yazılan, harflerin birbirine belirli formlarda bağlandığ 1 italik ya da kursiv yazıda harfler birleşik ve akıcı biçimde yazılır. Bazı harfler ise ligatür de denilen şekilde birleşerek yeni bir harf formu gibi görülür, örneğin:

(1) sözcük sonunda "č” ve "y" harflerinin ligatürü:

(2) sözcük sonunda "čc” ve "n" harflerinin ligatürü:

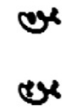

Bunun dışında standart biçim diyebileceğimiz ikinci türde ise yazı açık ve nispeten düz (eğimsiz) olarak yazılır ve son derece yaygın kullanılır. Diğer yandan, Turfan Vadisi metinlerinin büyük çoğunluğunda kursiv ve standart yazı formları birbirinden net olarak ayrılmazlar. Standart yazıyla yazılmış bir metinde bazı harflerin kursiv yazıdaki gibi birleştirilip bağlanması da mümkündür. Aşağ1da Mani yazısının italik ve standart yazı tiplerinde yazılmış metin örnekleri gösterilmektedir: 
Sekil 6. M 112 arsiv numaral kursiv yazll metin örnĕ̆ C $B B A W$

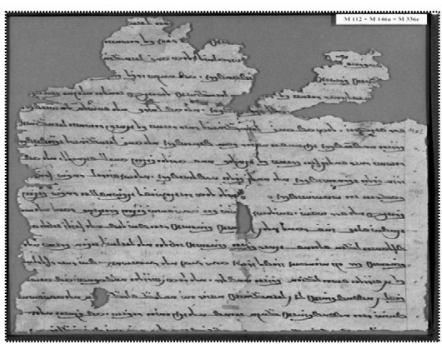

Sekil 7: U 10 arsiv numaralı standart yazılı metin örneği OBBAW

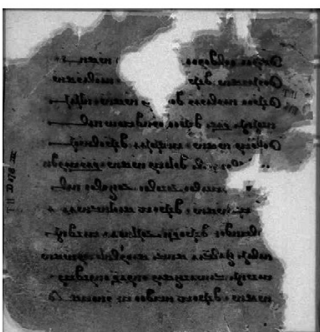

Bu iki yazı tipinden farklı olarak Mani yazısında özellikle başlıklar için kullanılan bir üçüncü bir yazı tipi de mevcuttur. Elbette, Latin harfleri gibi olmasa da bu harf serisi Mani yazısının majüskül biçimleri olarak değerlendirilebilir. Turfan metinlerinde bu yazı tipiyle sıkça karşılaşırız; özellikle, İran dillerinde yazılmış metinlerin bazılarının başlıklarındaki yoğun süsleme, ilk bakışta okuyucuya yazıdan çok resim izlenimi verir. Aşağıdaki tabloda "y", "s" ve "h" harflerinin başl1klarda ve metin içindeki görünümü gösterilmektedir (ilgili harfler yuvarlak içine alınmıştır) (Özbay, 2016: 21-23):

Tablo 2: Bașlık yazılarında Mani harflerinin görünümü

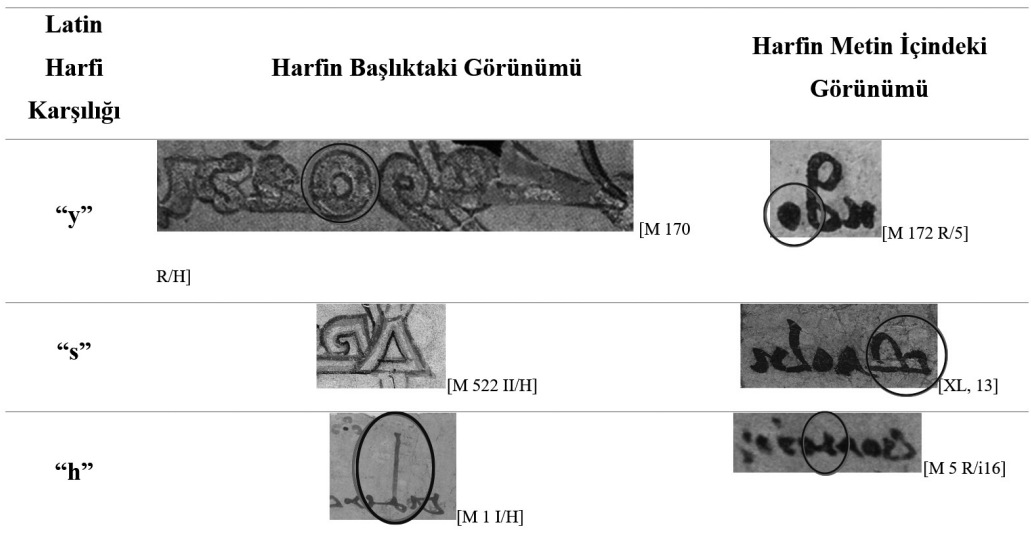

\section{Mani yazısında sayılar}

Mani yazısında Sami kökenli başka diğer yazılar gibi rakamlar ve sayı işaretleri de bulunmaktadır. Bu yazıda rakamlar için müstakil işaretler olmakla bir- 
likte Aramicede olduğu gibi bazı harflere de sayı değerleri yüklenebilir. Aşağıdaki tabloda Arami yazı grubundan Mani, Süryani (eski), Palmira ve Arami yazılarında ilk on sayı için kullanılan işaretler karşılaştırmalı olarak sunulmuştur: ${ }^{4}$

\begin{tabular}{|c|c|c|c|c|}
\hline & $\begin{array}{c}\text { MANI } \\
\text { YAZISI }\end{array}$ & SÜRYANI YAZISI & $\begin{array}{c}\text { PALMIRA } \\
\text { YAZISI }\end{array}$ & ARAMI YAZISI \\
\hline 1 & 1 & 1 & 1 & 1 \\
\hline 2 & $r$ & r & |I & II \\
\hline 3 & & $\mu$ & III & III \\
\hline 4 & سـ & $\mu \mu$ & IIII & IIII \\
\hline 5 & 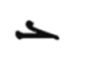 & & $y$ & II III \\
\hline 6 & ر & $1>$ & IV & III II \\
\hline 7 & ק & $r$ & IIy & $I \mathrm{M} \mathrm{n}$ \\
\hline 8 & حسب & $r p$ & my & II A III \\
\hline 9 & حسبر & דمיזו & nilly & DII $16 \mathrm{OH}$ \\
\hline 10 & $T$ & & $\longrightarrow$ & $-\rightarrow$ \\
\hline
\end{tabular}

Tabloda da görüldüğü gibi bu yazı grubunun sayı işaretleri ve sistemleri genel olarak örtüşmektedir. Turfan metinlerinden M 178 arşiv numarasıyla kayıtlı Soğdca yazmada bu işaretlerin büyük bir kısmını görebiliriz, örneğin:

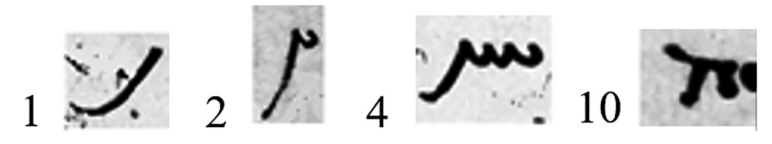

4 Sami kökenli yazılarda sayılarla ilgili ayrıntılı bilgi için krş. Özbay, 2016; Bennett, 1984; Duval, 1881; Gandz, 1932 ve Nöldeke, 1880. 


\section{Eski Uygurlarda Mani yazısı}

Manihaist Uygur metinleri de Turfan'daki İran metinleri gibi fragmanlar hâlinde bulunur. Dinî metinler ağırlıklı olarak İran dillerinden Soğdcadan Eski Uygurcaya tercüme edilmiştir. Dolayısıyla, Uygur Mani yazısı en çok Soğdların yazı geleneğinden etkiler barındırır. Manihaist Uygurlar metinlerini yazarken genellikle Mani yazısını tercih etmiş olsalar da Uygur yazılı ve Türk Runik yazılı Manici metinler de bulunur, hatta Runik yazılı İran metinleri bile vardır. 2000 y1lında Jens Wilkens Berlin Brandenburg Bilimler Akademisi, Turfan Araştırmaları Merkezinde bulunan Eski Uygur Manihaist metinlerinin kataloğunu yayımlar. $\mathrm{Bu}$ yayımda, koleksiyonda bulunan parçaların arşiv kayıt numaraları, parça üzerine yapılmış önceki çalışmalar, fiziki durumunu gösteren kayıtlar gibi genel değerlendirmeler bulunur. Katalog çalışması olduğu için Wilkens burada parçaların tek tek okumasını ya da metinlerin yazısındaki paleografik analizleri yapmaz; ancak parçanın daha rahat tespitini sağlayabilmek için her fragmanın yalnızca ilk ve son satırlarının yazı çevirisini yapar. Katalogda Eski Uygurca Manihaist eser külliyatı içeriklerine göre dokuzu ana başlık olmak üzere aşağıdaki gibi sınıflanır: ${ }^{5}$

1. Tarihî raporlar, hikâyeler, fabllar ve efsaneler

a. Hikâye ve efsaneler

b. Tarih raporları (misyonerlik tarihi vb.)

2. Vaazlar, dinî öğütler, emir ve yasalar

3. Öğretici metinler

a. Işığın bilgisi (Hikmet) ile ilgili vaazlar ve metinler

b. Ruhla ilgili vaazlar

c. Mani'nin büyük kitap fragmanları

4. Kozmoloji, kozmogoni, mitoloji ve eskatoloji metinleri

5. Ayin metinleri (ilahi, dua vb.)

6. Tövbe dualar1

a. Huastuanift' in parçası olabilecek tövbe duaları

b. Huastuanift ile ilgili olmayan tövbe duaları

7. Karışık içerikli metinler

5 Ayrıntılı bilgi için bk. Özbay, 2010: 12-13 ve krş. Wilkens, 2000: 5. 
8. Kişisel belgeler (mektup, diğer metinlerden ayrılmış ketebe kayıtları vb.)

9. İçeriği belirlenemeyen metinler (Uygur, Mani ve Runik yazılı fragmanlar)

a. Uygur yazısı ile yazılmış fragmanlar

b. Mani yazısı ile yazılmış fragmanlar

c. Runik yazı ile yazılmış fragmanlar

Yukarıda da görüldüğü gibi Berlin koleksiyonunda çok çeşitli türlerde yazılmış Manihaist Uygur metinleri mevcuttur. Mani yazısıyla üretilmiş Uygur metinleri İrani eserlere göre daha yakın tarihlidir; bu nedenle Uygur metinlerinde geleneksel diyebileceğimiz yazılara özgü ideogramlar, semboller bulunmaz ancak yazının görünüşü genel olarak aynıdır. Bunların dışında, yukarıda da belirttiğimiz üzere, Uygurlar Mani yazısını değiştirerek Türkçeye uyumlamışladır. Bunu yaparken özellikle Türkçedeki ünlü zenginliğini karşılayabilecek bir sistem geliştirmeye özen gösterdiklerini söyleyebiliriz. Aşağıda İran ve Uygur metinleri arasında genel olarak tespit edilen farklılıklar özetlenmektedir (Ayrıntılı bilgi için krş. Özbay, 2016: 283-287):

1.Diğer Orta İran dillerinde görülmeyen (ya da nadiren görülen) " $\beta$ ”, " $\delta$ ", “ $\gamma$ ” harfleri, Soğdcada sızıcı ünsüzleri göstermede kullanılırken Türkçede işlevleri şu şekilde değişir: $\quad \beta=\mathrm{v}, \quad \delta=\mathrm{d} \quad$ ve $\quad \gamma=\mathrm{g}$ (art sıradan ünlülerle birlikte)

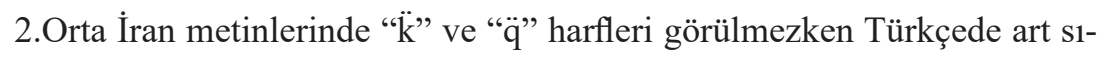
radan ünlülerle birlikte olan $\mathrm{k}$ ve g ünsüzlerini temsil eder.

3. Orta İran metinlerde t ünsüzünü göstermekte yaygın kullanılan " $t$ ” harfi Uygurcada çok az istisna dışında kullanılmaz, onun yerine " $t$ ” harfi kullanılır.

4. "w” harfi farklı kombinasyonlarla o, u, ö ve ü yuvarlak ünlüleri için kullanılır, İran metinlerinden farklı olarak ünsüz değeri yoktur (bazı dinî alıntı sözcükler dışında).

Yukarıda sıralanan maddelerden özellikle yuvarlak ünlülerin gösterimi için kullanılan "w" harfinin Türkçedeki o, u, ö ve ü yuvarlak ünlülerini temsili son derece dikkat çekicidir. Öte yandan, bu kullanım açık bir şekilde Mani yazılı Orta İran metinlerinden farklı olsa da ne yazık ki, yine o-u ve ö-ü ünlü çiftlerinin ayrımlarını yapmaz. Derlenen verilerden elde edinilen bilgilere göre yuvarlak ünlüler genel olarak Mani yazılı metinlerde aşağıdaki terkiplerle bulunur: ${ }^{6}$

6 Yuvarlak ünlülerin Mani yazısında gösterimiyle ilgili ayrıntılı bilgi için krş. Özbay, "The Orthography of the Rounded Vowels in Old Uyghur Manichean Texts" 2017. 


\begin{tabular}{|c|c|c|c|}
\hline & Başta & Ortada & Sonda \\
\hline$\underline{o}$ ünlüsü & $\begin{array}{l}\text { "elif"+ "w" } \\
\text { "elif"+ "w"+ "w" }\end{array}$ & $\begin{array}{l}\text { “w”" } \\
\text { “w”+ "w" (seyrek) }\end{array}$ & $\begin{array}{l}\text { "ww" } \\
\text { "ww"+ "w" }\end{array}$ \\
\hline$\underline{u}$ ünlüsü & “elif"+ "w" & $\begin{array}{l}\text { “w” } \\
\text { “w”+ "w” (seyrek) } \\
\varnothing\end{array}$ & $\begin{array}{l}\text { “w” } \\
\text { "ww"+ "w" }\end{array}$ \\
\hline$\underline{\partial}$ ünlüsü & $\begin{array}{l}\text { "elif"+ "w"+ "y" } \\
\text { "elif"+ "w" }\end{array}$ & $\begin{array}{l}\text { "w"+ "y" } \\
\text { "ww" }\end{array}$ & - \\
\hline 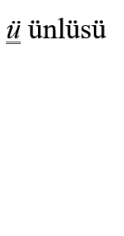 & "elif"+ "w"+ "y" & 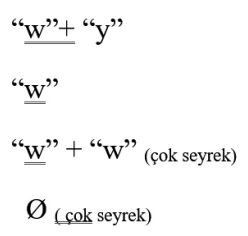 & $\begin{array}{l}\text { "w" } \\
\text { "w”+ "w" }\end{array}$ \\
\hline
\end{tabular}

\section{Sonuç}

Araştırmamızın gösterdiği en önemli bulgu, yazının yalnızca bir işaretler ya da harf dizisi olmadığı son derece etkili bir kültürel gösterge olduğudur. Manihaizm, Eski Uygur toplumuna getirdiği bütün yeniliklerle birlikte belki Bögü Kağan'ın da arzu ettiği gibi Uygurların Batı medeniyetiyle daha fazla kaynaşmasını sağlamıştır. Böylece, Eski Uygurlar İran halkları aracılığıyla yazı ve sayı sistemleri gibi k benzer olarak tırnak içindeki ikin ökleri Mısır'a ve eski kıtanın en gelişmiş uygarlıklarının doğduğu Babil'e uzanan muazzam bir medeniyetin entelektüel birikimine ulaşabilmişlerdir. Batıdan gelen İranlılar da Uygurlar sayesinde Uzak Doğu medeniyetine köprü kurabilmişlerdir. Makalemizin de konusu olan Mani yazısının Eski Uygurlardaki gelişimi ve kullanımı, bu medeniyetler etkileşiminin bir örneği niteliğindedir. Ayrıca, yukarıda örneklerle açıkladığımız gibi Eski Uygurlar edindikleri yeni bilgileri olduğu gibi kopyalamak yerine değiştirerek ve geliştirerek kendi dillerine uyumlu hâle getirebilmişlerdir. Uygur müstensihler, özellikle eserlerin yazımına azami dikkat göstermiş; yalnızca Mani alfabesini değil kullandıkları diğer yazıları da Türkçedeki sesleri doğru temsil edecek şekillerde geliştirmişlerdir. O gün izlenen bu hassas tutum sayesinde bu- 
gün Eski Türkçe metinlerin çoğunun yazı çevirisini (transkripsiyon) ciddi oranda yapabilmek mümkündür. Pek çok tarihî dilin en önemli sorunu olan ses değerlerinin doğruluğunun belirsizliği durumu, Eski Türkçe için mevcut olan önemli bir sorun değildir. Örneğin, son yıllarda Orta İran dillerinden Soğdca metinler üzerine yapılan çalışmalarda yalnızca harf çevirisi yapılabilmekte, ne yazık ki bu tarihî dil için okuma önerisi sunulamamaktadır. Bu nedenle, Uygur müstensihlerin özenli çalışmaları, Türk dilinin hem tarihî dönemleri hem de bugünü için son derece kıymetlidir. Öte yandan, Türk ve İran halkları arasında çok eski tarihlere uzanan dil ve yazı ilişkileri üzerine yapılacak yeni çalışmalar bu ilişkilerin farklı yönlerinin de aydınlanmasına olanak tanıyacaktır. 


\section{Kaynakça}

Andreas, F. C. - W. B. Henning (1932), "Mitteliranische Manichaica aus Chinesisch-Turkestan I”, SPAW. Phil-hist. K1., s. 173-222.

Andreas, F. C. - W. B. Henning (1933), "Mitteliranische Manichaica aus Chinesisch-Turkestan II”, SPAW. Phil.-hist. K1., s. 292-363.

Andreas, F. C. - W. B. Henning (1934), "Mitteliranische Manichaica aus Chinesisch-Turkestan III”, SPAW. Phil.-hist. Kl., s. 846-912.

Bennett, P. R. (1984), Comparative, Semitic Linguistics A Manuel. Indiana.

Boyce, M. (1960), A Catalogue of the Iranian Manuscripts in Manichean Script in the German Turfan Collection. Berlin. (DAW. Institut für Orientforschung. 45.)

Clark, L. (2013), Uygur Manichaean Texts. Volume II: Liturgical Texts. Text, Translation, Commentary, Turnhout. (Corpus fontium Manichaeorum. Series Turcica 2)

Colditz, I. (2013), "Die Manuskriptologie der iranisch-manichäischen Turfantexte”, Handbuch der Iranistik, Ed. L. Paul. Wiesbaden, s. 352-360.

Durkin-Meisterernst, D. (2000), "Erfand Mani die manichäische Schrift?”, Studia Manichaica. IV. Internationaler Kongreß zum Manichäismus, Berlin 14.-18. Juli 1997, Ed. Ronald E. Emmerick, W. Sundermann and P. Zieme. Berlin, s. 161-178. (Berichte und Abhandlungen. BBAW. Sonderband. 4.)

Durkin-Meisterernst, D. (2004), Dictionary of Manichaean Texts. Vol. III: Texts from Central Asia and China. Part 1: Dictionary of Manichaean Middle Persian and Parthian. Turnhout. (Corpus fontium Manichaeorum: Subsidia.)

Durkin-Meisterernst, D. (2014), Grammatik des Westmitteliranischen (Partisch und Mittelpersisch). Wien, 2014. (ÖAW. Sitzungsberichte der Phil.-hist. K1. 850. Veröffentlichungen zur Iranistik 73. Grammatica Iranica. 1.)

Duval, R. (1881), Traité de Grammaire Syriaque. Paris.

Faulmann, K. (1986), Das Buch der Schrift: enthaltend die Schriftzeichen und Alphabete aller Zeiten und aller Völker des Erdkreises. Hildesheim-Zürich-New York.

Gandz. S. (1932-33), "Hebrew Numerals”, American Academy for Jewish Research, (4), s. 53-112.

Kara, Gy. (1996), “Aramaic Scripts for Altaic Languages”, The World's Writing Systems, Ed. P. T. Daniels - W. Bright. New York - Oxford, s. 536-556.

Le Coq, A. von. (1911), "Dr. Stein's Turkish Khustuanift From Tun-huang, Being a ConfessionPrayer of The Manichæn Auditores", JRAS, s. 277-314.

Le Coq, A. von. (1912), Türkische Manichaica aus Chotcho I. Berlin, 1912. (APAW. Phil.-hist. K1. 1911. Anhang: Abhandlungen nicht zur Akademie gehöriger Gelehrter. 6.) [T1pk1basım: SEDTF 1, 393-451] 
Le Coq, A. von. (1919), Türkische Manichaica aus Chotcho II. Berlin. (APAW. Phil.-hist. Kl. 1919:3) [Tipkıbasım: SEDTF 1, 452-464]

MacKenzie, D. N. (1971), A concise Pahlavi dictionary. London.

Montgomery, J. A. (1913), Aramaic Incantation Texts from Nippur, Philadelphia.

Morano, E. (2007), “A Working Catalogue of the Berlin Sogdian Fragments in Manichaean Script", Iranian Languages and Text from Iran and Turan Ronald E. Emmerick Memorial Volume, Ed. M. Macuch, M. Maggi and W. Sundermann, Wiesbaden, s. 239-270. (Iranica. 13.)

Müller, F. W. K. (1904), Handschriften-Reste in Estrangelo-Schrift aus Turfan, ChinesischTurkistan. II. Teil. Berlin, 1904. (AKPAW 1904. Anhang: Abhandlungen nicht zur Akademie gehöriger Gelehrter. Philosophische und historische Abhandlungen. 2.) [tıpkıbasim: SEDTF 3, 7-123]

Nöldeke, T. (1880), Kurzgefasste Syrische Grammatik, Leipzig.

Özbay, B. (2010), Maniheist Uygur Metinlerinin Envanterinin Hazırlanması, (Yayımlanmamış yüksek lisans tezi) Yıldız Teknik Üniversitesi, İstanbul.

Özbay, B. (2014), Huastuanift Manihaist Uygurların Tövbe Duası, Ankara. (AKDTYK TDK 1127. Eski Uygurca Kütüphanesi 3.) [2. bask1 2019]

Özbay, B. (2015), "Manihaist Orta İran ve Eski Uygur Metinlerinde /t/ ve /t/ seslerinin yazımı”, Türk Dilleri Araştırmalar1-Summer-2013, Vol. 23,1. İstanbul.

Özbay, B. (2016), The Paleographical Analysis of the Manichean Script for Middle Iranian and Old Uyghur Texts, (Yayımlanmamış doktora tezi) Yıldız Teknik Üniversitesi, İstanbul.

Özbay, B. (2017), “The Orthography of the Rounded Vowels in Old Uyghur Manichean Texts", $9^{\text {th }}$ International Conference of the IAMS to be held at the University of Turin and MAO, Turin, Italy, $11^{\text {th }}$ September- $15^{\text {th }}$ September 2017. (Baskıda)

Özertural, Z. (2008), Der uigurische Manichäismus, Neubearbeitung von Texten aus Manichaica I und III von Albert v. Le Coq, Wiesbaden. (VdSUA. 74.)

Pedersen, N. A., \& J. M. Larsen (2013), Manichaean Texts in Syriac, Turnhout.

Sims-Williams, N. (1981), "The Sogdian Sound-System and the Origins of the Uyghur Script", JA $269,347-360$.

Sundermann, W. (1997), "The Manichaean Texts in Languages and Scripts of Central Asia", Languages and Scripts of Central Asia, Ed. S. Akiner and N. Sims-Williams, London, s. $39-45$.

Wilkens, J. (2000), Alttürkische Handschriften. Teil 8. Manichäisch-türkische Texte der Berliner Turfansammlung, Stuttgart. (VOHD 13, 16)

Zieme, P. (1975), Manichäisch-türkische Texte. Texte, Übersetzung, Anmerkungen, Berlin. (BTV) 